\title{
LEVO- $\alpha$-ACETYLMETHADOL (LAAM) INDUCED QTC-PROLONGATION - Results from a Controlled Clinical Trial
}

\author{
H. Wieneke ${ }^{1 *}$, H. Conrads²*, J. Wolstein²,3, F. Breuckmann ${ }^{1}$, M. Gastpar ${ }^{2}$, R. Erbel ${ }^{1}$, N. Scherbaum ${ }^{4}$ \\ ${ }^{1}$ Department of Cardiology, University Hospital Essen, \\ ${ }^{2}$ Department of Psychiatry and Psychotherapy, Rhine State Hospital, University of Duisburg-Essen, \\ ${ }^{3}$ Department of Psychology, University of Bamberg \\ ${ }^{4}$ Addiction Research Group at the Department of Psychiatry and Psychotherapy, Rhine State Hospital, University of Duisburg-Essen, \\ Germany
}

\begin{abstract}
Background: Due to potential proarrhythmic side-effects levo- $\alpha$-Acetylmethadol (LAAM) is currently not available in EU countries as maintenance drug in the treatment of opiate addiction. However, recent studies and meta-analyses underline the clinical advantages of LAAM with respect to the reduction of heroin use. Thus a reappraisal of LAAM has been demanded. The aim of the present study was to evaluate the relative impact of LAAM on QTc-interval, as a measure of pro-arrhythmic risk, in comparison to methadone, the current standard in substitution therapy.

Methods: ECG recordings were analysed within a randomized, controlled clinical trial evaluating the efficacy and tolerability of maintenance treatment with LAAM compared with racemic methadone. Recordings were done at two points: 1) during a run-in period with all patients on methadone and 2) 24 weeks after randomisation into methadone or LAAM treatment group. These ECG recordings were analysed with respect to QTc-values and QTc-dispersion. Mean values as well as individual changes compared to baseline parameters were evaluated. QTc-intervals were classified according to CPMP-guidelines.

Results: Complete ECG data sets could be obtained in 53 patients (31 LAAM-group, 22 methadone-group). No clinical cardiac complications were observed in either group. After 24 weeks, patients receiving LAAM showed a significant increase in QTc-interval $(0.409 \mathrm{~s}$ $\pm 0.022 \mathrm{~s}$ versus $0.418 \mathrm{~s} \pm 0.028 \mathrm{~s}, \mathrm{p}=0.046$ ), whereas no significant changes could be observed in patients remaining on methadone. There was no statistically significant change in QTc-dispersion in either group. More patients with borderline prolonged and prolonged QTc-intervals were observed in the LAAM than in the methadone treatment group ( $\mathrm{n}=7$ vs. $\mathrm{n}=1$; $\mathrm{p}=0.1)$.

Conclusions: In this controlled trial LAAM induced QTc-prolongation in a higher degree than methadone. Given reports of severe arrhythmic events, careful ECG-monitoring is recommended under LAAM medication.
\end{abstract}

*Both authors contributed equally.
Key words: LAAM, methadone, opiate addiction, cardiac arrhythmia, QTc-interval

\section{INTRODUCTION}

The synthetic opioid levo- $\alpha$-acetylmethadol (LAAM) is a long-acting full $\mu$-opioid agonist which was approved by the U.S. Food and Drug Administration (FDA) for maintenance treatment of opioid dependence in 1993. There are many studies comparing the efficacy and safety of LAAM with methadone as medication in maintenance treatment for heroin addiction [1-4]. In clinical trials, LAAM was found to be comparable to methadone with respect to reduction of illicit opiate use, treatment retention, employment, clinic attendance, and involvement in illegal activities [5]. The safety of LAAM in long-term treatment was similar to that of methadone in a meta-analysis [6].

Reports of cases of life-threatening ventricular arrhythmias (especially torsade de pointes) have raised concerns about potential arrhythmogenic effects both of LAAM [7, 8] and methadone [9, 10]. Both LAAM and methadone belong to a group of drugs that block cardiac potassium channels responsible for mediating ventricular repolarisation [11]. In the context of these cardiac side effects, the European Medicines Agency (EMEA) recommended the suspension of the marketing authorization for LAAM in 2001 and the United States Food and Drug Administration (FDA) required the addition of a "black box" warning on the LAAM label [12]. However, a recent study showing higher efficiency of LAAM with respect to suppression of heroin use revived the discussion whether potential risks for cardiac arrhythmias really outweigh the advantages of LAAM $[13,14]$.

In clinical practice, the prolongation of the QT-interval (time interval including myocardial de- and repolarisation) is a surrogate marker for the risk of developing torsades de pointes tachycardia (TdP) [15]. Little is known regarding the extent of LAAM-induced QT-prolongation and the relative risk of LAAM compared with racemic methadone for the occurrence of QT-prolongation. Therefore the aim of the present study was to analyse corrected QT-duration and QT- 
dispersion as measures of potential arrhythmogenic effects of LAAM in comparison to methadone.

\section{Methods}

\section{SUBJECTS}

ECG recordings were obtained from participants in a phase III clinical trial [16]. Heroin addicts on methadone maintenance treatment for at least one month with a stable methadone dosage for at least two weeks were eligible for the study. Inclusion criteria were age between 18 to 65, diagnosis of opioid dependence, daily methadone dose less than $100 \mathrm{mg}$ methadone hydrochloride, negative urine drug screen for opiates during the screening period, negative pregnancy test and absence of significant other psychiatric or somatic illness. Subjects with known cardiac disease were excluded. The trial was endorsed and supervised by the Bundesinstitut für Arzneimittel und Medizinprodukte (German Federal Institute for Drugs and Medical Devices, Project Nr. 43048 20) and approved by all local ethics committees. All patients provided written informed consent to their participation in the study.

\section{STUdy DESIGN}

The parent study was designed as an open, multi-centre, flexible dose, parallel-group, randomised trial [16]. The study consisted of two parts: the run-in period and the treatment phase (Fig. 1). During the run-in phase, all patients received standardised treatment with racemic methadone solution. At the end of the run-in phase, patients were randomly allocated to one of two treatment groups in a 1:1 ratio: LAAM dispersible tablets 3 times/week (treatment group I) or racemic methadone solution daily (treatment group II). The maximum dosage was $100 \mathrm{mg} /$ day of methadone or $130 \mathrm{mg}$ LAAM on Mondays and Wednesdays and $160 \mathrm{mg}$ on Fridays (1.3 and 1.6 times the daily methadone dose).

During the treatment period (weeks 1 to 24), outpatient visits were performed every week. The individual endpoint assessment of all efficacy and safety parameters including an ECG recording was carried out after regular completion (week 24) or premature discontinuation of the study (Fig. 1).

\section{URINE TESTING}

Urine drug-screening was carried out randomly two times per week. To minimise the risks of manipulation of the urine sample, the fresh urine was checked on temperature using the Franklin collector [17].

\section{ECG-RECORDINGS}

Surface resting ECG recordings were performed in a standard 12-lead manner at the beginning of the runin period and in week 24 of the treatment period in all participating centres. The "week 24" ECG-recording was performed at the individual end of study, which could be after 24 weeks of randomised treatment or at the time of early discontinuation.

\section{DATA ANALYSIS}

Each ECG-recording was analysed in accordance with the CPMP-guidelines [18]. ECG-analysis was blinded for the assigned treatment groups. The following parameters were determined.

QTc-interval: The QT-interval was measured in three consecutive beats in lead Einthoven II, and the arithmetic mean of these values was calculated [19]. The corrected QT-interval (QTc-interval) was then calculated using Bazett's-formula (QTc $=\mathrm{QT} / \mathrm{SQR} \mathrm{RR})$ $[20,21]$.

QTc-dispersion (QTD): QTD is defined as the difference between the maximum and minimum QTc-interval in a 12 lead electrocardiogram. QTD values were calculated as the arithmetic mean over the three considered complexes [22].

\section{CPMP-CLASSIFICATION}

According to the CPMP-guidelines the following classifications are used.

QTc-interval values:

$\begin{array}{lll} & \begin{array}{l}\text { Adult Males } \\ \text { Normal }\end{array} & \begin{array}{l}\text { Adult Females } \\ \leq 430 \mathrm{~ms}\end{array} \\ \text { Borderline } & 431-450 \mathrm{~ms} & 451-470 \mathrm{~ms} \\ \text { Prolonged } & >450 \mathrm{~ms} & >470 \mathrm{~ms}\end{array}$

\section{Changes of QTC-INTERVAl under Medication}

Difference <30 ms: Unlikely to raise significant concerns about the potential risk of a drug induced arrhythmia including TdP (increased risk unlikely).

Difference 30-60 ms: More likely to represent a drug effect, raising concern about the potential risk of a drug to induce arrhythmias including TdP (increased risk possible).

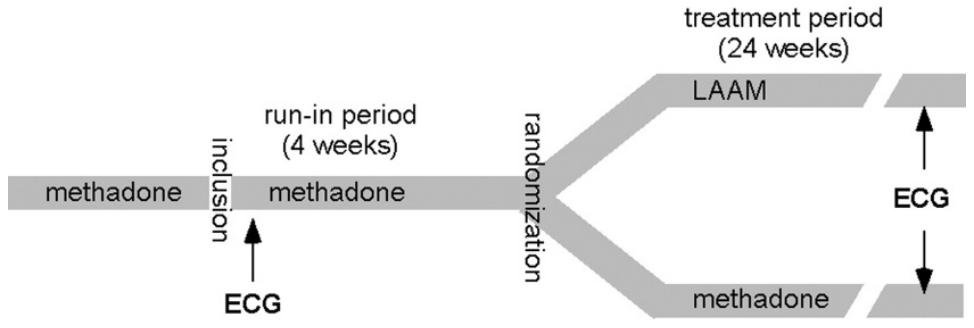

Fig. 1. Study design. ECG recordings were done at the beginning of the run-in period and at the end of the treatment period. 
Difference $>60$ ms: Clear concerns about the potential risk of a drug to induce arrhythmias including TdP (increased risk probable).

\section{QTC-DISPERSION}

An increased risk of arrhythmia is assumed when the absolute QTc-dispersion is $>100 \mathrm{~ms}$ or the change in QTc-dispersion is $>100 \%$.

\section{STATISTICAL ANALYSIS}

Data are given as means \pm standard deviation. Continuous variables were compared before and during treatment using t-test for dependent samples. Differences between treatment groups with regard to the incidence of classes according to CPMP-classification were analysed using chi-square statistics. P-values $<0.05$ were considered statistically significant. Data analysis was performed with the SPSS (Version 8.0).

\section{RESULTS}

84 patients were initially enrolled into the clinical trial. Only patients with complete ECG data sets were included in the data analysis. Complete data sets of two ECGs could be obtained for 53 patients (31 LAAM- group, 22 methadone-group). The average dosages of methadone or LAAM were comparable in both groups in the run-in and in the treatment phase. For patient characteristics see Table 1.

No faints, syncopes or other clinical signs of cardiac disease were observed either in the LAAM group or in the methadone group. Urine drug screening revealed continuous use of cocaine during the study in one patient with abnormal QTc intervals. Another patient with that abnormality received a tricyclic antidepressant. Both patients were in the LAAM group and had normal QTc intervals while receiving methadone in the run-in phase.

\section{ECG - PARAmetric AnAlysis}

Mean QTc-interval before starting study medication was $0.409 \mathrm{~s} \pm 0.022 \mathrm{~s}$ in the LAAM group and $0.406 \mathrm{~s}$ $\pm 0.029 \mathrm{~s}$ in the methadone group, respectively. There were no significant differences between both groups. A significant increase in QTc-interval in the LAAM group was observed after 24 weeks or at the endpoint of individual study treatment, respectively $(0.409 \mathrm{~s} \pm$ $0.022 \mathrm{~s}$ at run-in versus $0.418 \mathrm{~s} \pm 0.028 \mathrm{~s}$ at 24 weeks, $\mathrm{p}$ $=0.046)$. In contrast, no significant change occurred in the methadone group $(0.406 \mathrm{~s} \pm 0.029 \mathrm{~s}$ at run-in versus $0.405 \mathrm{~s} \pm 0.025 \mathrm{~s}$ at 24 weeks) (Fig. 2).

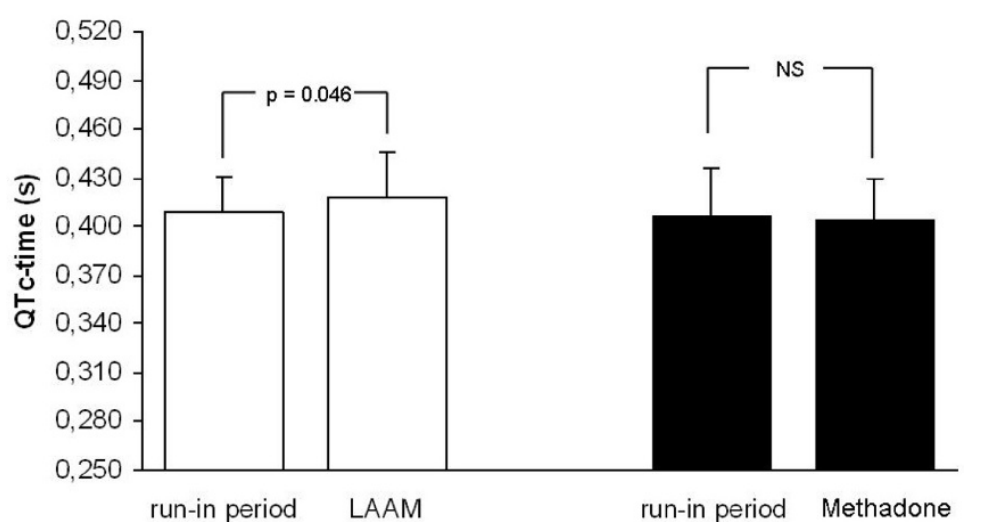

Fig. 2. Comparison of QTc intervals between runin and treatment phase separately analysed for the methadone- and LAAM-group. Mean \pm SD.

Table 1. Patient characteristics in both study groups and average dosages during run-in phase and treatment phase in both groups.

\begin{tabular}{l|l|l|l}
\hline Treatment Group & \multicolumn{1}{|c}{$\begin{array}{c}\text { Methadone } \\
\text { (METH) }\end{array}$} & \multicolumn{1}{|c}{ LAAM } \\
\hline Total number (n) & 22 & 31 & $11 \mathrm{~F} / 20 \mathrm{M}$ \\
\hline Gender & $12 \mathrm{~F} / 10 \mathrm{M}$ & $27.9 \mathrm{yrs}$ & \multicolumn{2}{|l}{} \\
\hline Age (avg) & $31.0 \mathrm{yrs}$ & $73.5 \pm 25.7 \mathrm{mg}$ daily & Fri \\
\hline $\begin{array}{l}\text { Average dosage during run-in period } \\
\text { (METH in both groups) }\end{array}$ & $72.0 \pm 25.5 \mathrm{mg}$ daily & Mon \& Wed & $109.7 \pm 39.5 \mathrm{mg}$ LAAM \\
\hline \begin{tabular}{l} 
Average dosage during treatment phase \\
\cline { 2 - 3 }
\end{tabular} & $69 \pm 27.6 \mathrm{mg}$ METH & $89.6 \pm 32.4 \mathrm{mg}$ LAAM & $\begin{array}{l}\text { equiv. to } 68.6 \pm 24.7 \mathrm{mg} \\
\text { METH* }\end{array}$ \\
\cline { 2 - 4 }
\end{tabular}

*For better comparability, METH equivalents are shown in the LAAM groups assuming a factor of 1.3 (Monday \& Wednesday) and 1.6 (Friday). 


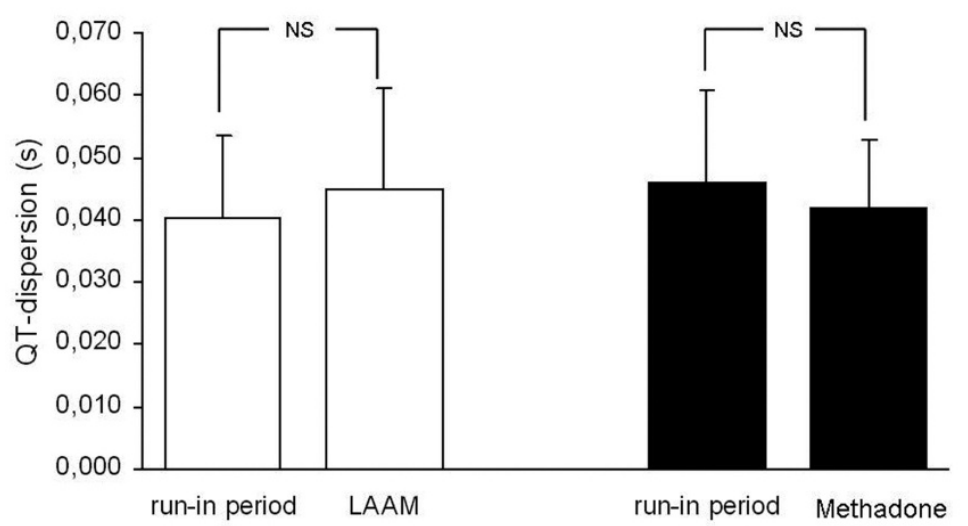

Fig. 3. Comparison of QT-dispersion between run-in and treatment phase separately analysed for the methadone- and LAAM-group. Mean \pm SD.
QT-dispersion before starting study medication was $0.040 \mathrm{~s} \pm 0.013 \mathrm{~s}$ in the LAAM group and $0.046 \mathrm{~s} \pm$ $0.015 \mathrm{~s}$ in the methadone group. There were no significant differences between both groups. There was a non-significant increase in QT-dispersion in the LAAM group $(0.045 \pm 0.016 \mathrm{~s} ; \mathrm{p}=0.19)$ at 24 weeks and a non-significant decrease in the methadone group at 24 weeks $(0.042 \mathrm{~s} \pm 0.011 \mathrm{~s})$ (Fig. 3).

\section{ECG - NON-PARAMETRIC ANALYSIS}

Patients were classified according to the CPMP-classification. Before randomisation in the LAAM-group, 2 patients had borderline QTc-intervals and 1 patient had prolonged QTc-intervals. After 24 weeks of medication with LAAM, 4 patients showed borderline QTc-intervals and 3 patients showed prolonged QTcintervals. Therefore, when considering both borderline and prolonged QTc-intervals as abnormal, 3 patients showed abnormal QTc-intervals before randomisation and 7 patients showed abnormal QTc-intervals after 24 weeks of LAAM treatment. In the methadone group 1 patient showed borderline prolonged QTc-intervals and 1 patient showed prolonged QTc-intervals before randomisation. After 24 weeks of methadone treatment 1 case of borderline prolongation and no case of prolonged QTc-intervals could be observed. Taking borderline and prolonged QTc-intervals together more patients with QTc-prolongation were observed in the LAAM treatment group than in the methadone treatment group ( $\mathrm{n}=7$ vs. $\mathrm{n}=1)$ ), however this did not reach statistical significance $(p=0.1)$. According to the CPMP-guidelines, 2 patients in the LAAM group showed an increase in QTc-interval between 30 and $60 \mathrm{~ms}$ and 2 patients $>60 \mathrm{~ms}$ after a treatment period of 24 weeks or at the endpoint of individual study treatment, respectively. In the methadone group 1 patient showed an increase in QTc-interval between 30 und $60 \mathrm{~ms}$. The difference between both groups was not significant.

\section{Discussion}

Methadone, introduced in the late 1960s, and LAAM, approved in 1993 by the FDA as maintenance drug, are two full $\mu$-opioid agonists. Clinical studies suggest that LAAM is at least as efficient for substitution treatment as methadone. In addition, LAAM provides the option of less-than-daily doses which is made pos- sible by the long half-lives of its two active metabolites. However, reports on potential proarrhythmic side-effects of LAAM raised concerns about its role as therapy for opiate dependence. Thus the European Medicines Agency (EMEA) recommended to suspend the marketing authorization for LAAM in 2001, and the United States Food and Drug Administration (FDA) required the addition of a "black box" warning on the LAAM label.

Prompted by recent reports on potential advantages of LAAM with respect to promoting reduction of opiate use, the need of a re-evaluation of LAAM has been demanded [13, 24, 25]. Thus the aim of the present study was to compare specific ECG changes in patients on LAAM and methadone substitution, the current standard in opioid substitution. The main finding of the present randomized study in opioid addicts is that switching from methadone to LAAM treatment increases the mean QTc-interval and the number of individual patients with abnormal QTc-interval compared with patients continuously on racemic methadone.

To our knowledge there is only one randomized study by Wedam et al. [26] examining the effect of methadone, LAAM and buprenorphine on QT-intervals. They found that the incidence of prolonged QTcintervals were considerable higher with LAAM and methadone than with buprenorphine. LAAM showed a tendency towards enhanced absolute QTc-values and an increase under medication as compared to methadone, what is in concordance with our findings.

There are several studies investigating QTc-prolongation and cardiac arrhythmia in patients on methadone [9, 10, 27, 28]. Generally, QTc-interval is increased as compared with patients taking heroin [29] or with a reference group with the same age and sex [30]. Clinical complications and arrhythmias under methadone medication have predominantly been observed under high dosages (markedly more than $100 \mathrm{mg}$ per day) [28], whereas mean daily methadone dosage was $69 \mathrm{mg}$ in our study. As in the present study patients were on methadone during the run-in period, the rise in QTc-intervals and the increase of patients with prolonged QTc-intervals under LAAM medication might point to a higher pro-arrhythmic impact of LAAM when taking QTc-interval as a surrogate marker for arrhythmic risk.

In several clinical and epidemiological studies the reliability of the QT-interval measurements in the lead Einthoven II has been validated [31]. A prolongation of the QTc-interval is associated with an increased risk of 
malignant ventricular arrhythmias [15], mainly in patients with prior cardiovascular disease [32]. However, a direct cause-effect relation between a prolonged QTcinterval and the occurrence of ventricular arrhythmias has not been established [33]. In addition to the drug induced change of mean values of QTc-intervals in a population, the effect of the drug on QTc-intervals in individual patients has to be assessed. The evaluation of individual cases is of special interest as there is a particular predisposition for the occurrence of torsades de pointes tachycardias in certain individuals [34]. On the basis of observational studies it has been speculated that ion channel single nucleotide polymorphisms (SNPs) may be partially responsible for this susceptibility [35]. Thus if a patient develops a marked prolongation of the QTc-interval, this must be considered as a significant and potentially serious drug effect which might be more important than a slight increase in mean values described in a sample of patients [36].

Given our results and the literature, there should be a careful weighing up of the pros and cons regarding the availability of LAAM as maintenance drug in the EU. On the one hand, LAAM is a maintenance drug of proven efficacy and with some advantages compared to methadone. On the other hand, there is an increased risk of cardiac complications. We agree with Stimmel [37] that the known cardiac risk should lead to the improvement of cardiac monitoring, but not to a principal withdrawal of LAAM from the market. Known risk factors for cardiac side effects under LAAM are previous cardiovascular disease, excess doses of LAAM, medication inhibiting the P450-3A4 system, and medication lowering serum potassium or magnesium. Taking these factors into account, Stimmel [37] recommended a baseline ECG in all patients prior to LAAM treatment with a subsequent exclusion of patients with prolonged QTc-interval. Additional ECGs should be performed two weeks after onset of LAAM treatment and after every substantial change of dosage. Eventually, in individual cases there might be the dilemma between the risk of continuous heroin use and the risk of cardiac complications under methadone or LAAM treatment [38].

\section{LIMITATION}

84 subjects were initially enrolled in the study and 53 complete ECG data sets could be obtained. This discrepancy was due to lack of compliance with study procedures, e.g. drop-out from study treatment. It reflects the difficulties in conducting clinical studies in this patient group and has also been reported from other studies [39].

QTc-intervals and QT-dispersion represents only surrogate markers for an increased risk for arrhythmias. The present study is not powered to evaluate hard endpoints as sudden cardiac death. Notwithstanding QTc-interval is the best surrogate marker for TdP at the moment.

\section{CONCLUSION}

In the present study we could show that an indicator for an increased risk for cardiac arrhythmia was signif- icantly more pronounced in patients after switching from methadone to LAAM compared with patients remaining on methadone. This suggests that LAAM might have a higher potential to induce cardiac arrhythmias than does methadone in comparable dosages, however, no clinical cardiac symptoms were reported in either group. In sum, in patients with known cardiac risk factors, methadone might be preferable to LAAM, but the statement of Jaffe [14] should be seriously considered that it would be beneficial for opiate addicted patients if LAAM were available as a maintenance drug.

Statement of Interest: The study was supported by Hexal (Germany).

\section{REFERENCES}

1. Jaffe JH, Senay EC, Schuster CR, Renault PR, Smith B, DiMenza S. Methadyl acetate vs. methadone: A doubleblind study in heroin users. JAMA 1972;222:437-42.

2. Senay EC, Dorus W, Renault RF. Methadylacetate and methadone: An open comparison. JAMA 1977;237:13842.

3. Trueblood B, Judson BA, Goldstein A. Acceptability of methadyl acetate (LAAM) as compared with methadone in a treatment program for heroin addicts. Drug Alcohol Depend 1978;3:125-32.

4. Freedman RR, Czertko G. A comparison of thrice weekly LAAM and daily methadone in employed heroin addicts. Drug Alcohol Depend 1981;8:215-22.

5. Glanz M, Klawansky S, McAullife W, Chalmers T. Methadone vs. L-alpha-acetyl-methadol (LAAM) in the treatment of opiate addiction. A meta-analysis of the randomized, controlled trials. Am J Addict. 1997;6(4):339-49.

6. Clark N, Lintzeris N, Gijsbers A, Whelan G, Dunlop A, Ritter A, Ling W. LAAM maintenance vs methadone maintenance for heroin dependence. Cochrane Database Syst Rev. 2002;(2):CD002210.

7. Deamer RL, Wilson DR, Clark DS, Prichard JG. Torsades de pointes associated with high dose levomethadyl acetate (ORLAAM). J Addict Dis 2001;20(4):7-14.

8. European Agency for the Evaluation of Medical Products. EMEA public statement to suspend the marketing authorisation for Orlaam (levoacetylmethadol) in the European Union. April 19, 2001; EMEA/8776/01. Available at: http://www.emea.eu.int/pdfs/-human/press/pus/87 7601en.pdf.

9. Sala M, Anguera I, Cervantes M. Torsade de pointes due to methadone. Ann Intern Med. 2003; 139: W64.

10. Mokwe EO, Ositadinma O. Torsade de pointes due to methadone. Ann Intern Med. 2003; 139: W64.

11. Katchman AN, Mcgroary KA, Kilborn MJ, Kornick CA, Manfredi PL, Woosley RL, Ebert SN. Influence of Opioid Agonists on Cardiac Human Ether-a-go-go-related Gene K+ Currents. J Pharmacol Exp Ther 2002; 303: 688-94.

12. U.S. Food and Drug Administration: Product Discontinuation Notice. ORLAAM ${ }^{\circledR}$ (Levomethadyl hydrochloride acetate) Oral Solution, $10 \mathrm{mg} / \mathrm{mL}$, CII. 2003 Available at http://www.fda.gov/cder/drug/shortages/orlaam.htm.

13. Anglin MD, Conner BT, Annon J, Longshore D. Levo-alpha-acetylmethadol (LAAM) versus methadone maintenance: 1 -year treatment retention, outcomes and status. Addiction 2007 Sep;102(9):1432-42.

14. Jaffe JH. Can LAAM, like Lazarus, come back from the dead? Addiction 2007;102: 1342-3.

15. Akhtar M. Clinical spectrum of ventricular tachycardia. Circulation 1990;82: 156-73. 
16. Wolstein J, Gastpar M, Finkbeiner T, Heinrich C, Heitkamp R, Poehlke T, Scherbaum N. A Randomized, Open-label Trial Comparing Methadone and Levo-alphaacetylmethadol (LAAM) in Maintenance Treatment of Opioid Addiction: Pharmacopsychiatry (in press).

17. Ling W, Wesson DR, Charuvastra C, Klett J: A controlled trial comparing buprenorphine and methadone maintenance in opioid dependence. Arch Gen Psychiatry 1996;53:401-7.

18. Committee for Proprietary Medicinal Product (CPMP). Points to consider: the assessment of the potential for QT interval prolongation by non-cardiovascular drugs. The European Agency for the Evaluation of Medicinal Products 1997.

19. Garson A. How to measure the QT interval - what is normal. Am J Cardiol 1993;72: 14B-22B.

20. Algra A, Tijssen JG, Roelandt JR, Pool J, Lubsen J. QTc prolongation measured by standard 12-lead electrocardiography is an independent risk factor for sudden death due to cardiac arrest. Circulation 1991;83:1888-94.

21. Bazett HC. An analysis of time relations of the electrocardiogram. Heart 1920;7:353-70.

22. De Bruyne MC, Hoes AW, Kors JA, Hofman A, Bemmel JH, Grobbee DE. QTc dispersion predicts cardiac mortality in the elderly. The Rotterdam Study. Circulation 1998;97:467-72.

23. Clark N, Lintzeris N, Gijsbers A, Whelan G, Dunlop A, Ritter A, Ling W. LAAM maintenance vs methadone maintenance for heroin dependence. Cochrane Database Syst Rev. 2002;(2):CD002210.

24. Ritter AJ, Lintzeris N, Clark N, Kutin JJ, Bammer G, Panjari M. A randomized trial comparing levo-alpha acetylmethadol with methadone maintenance for patients in primary care settings in Australia. Addiction. 2003;98: 1605-13.

25. Longshore D, Annon J, Anglin MD, Rawson RA. Levoalpha-acetylmethadol (LAAM) versus methadone: treatment retention and opiate use. Addiction. 2005; 100: 1131-9.

26. Wedam EF, Bigelow GE, Johnson RE, Nuzzo PA, Haigney MC. QT-interval effects of methadone, levomethadyl, and buprenorphine in a randomized trial. Arch Intern Med. 2007;167:2469-75.

27. Kornick CA, Kilborn MJ, Santiago-Palma J, Schulman G, Thaler HT, Keefe DL, Katchman AN, Pezzullo JC, Ebert SN, Woosley RL, Payne R, Manfredi PL. QTc interval prolongation associated with intravenous methadone. Pain 2003;105:499-506.

28. Krantz MJ, Lewkowiez L, Hays H, Woodroffe MA, Robertson AD, Mehler PS. Torsade de pointes associated with very-high-dose methadone. Ann Intern Med. 2002;137(6):501-4.

29. Ehret GB, Voide C, Gex-Fabry M, Chabert J, Shah D, Broers B et al. Drug-induced long QT syndrome in injection drug users receiving methadone: high frequency in hospitalized patients and risk factors. Arch Intern Med. 2006; 166: 1280-1287.
30. Maremmanni I, Pacini M, Cesaroni C, Lovrecic M, Perugi G, Tagliamonte A. QTc interval prolongation in patients on long-term methadone maintenance therapy. Eur Addict Res 2005;11: 44-9.

31. Woosley RL, Sale M. QT interval: a measure of drug action. Am J Cardiol 1993;26:36B-43B.

32. Montanez A, Ruskin JN, Hebert PR, Lamas GA, Hennekens CH. Prolonged QTc interval and risks of total and cardiovascular mortality and sudden death in the general population: a review and qualitative overview of the prospective cohort studies. Arch Intern Med. 2004; 164: 943-8.

33. Morganroth J. Relations of QTc prolongation on the electrocardiogram to torsades de pointes: definitions and mechanisms. Am J Cardiol 1993;72: 10B-13B.

34. Houltz B, Daroö B, Edvardsson N et al. Electrocardiographic and clinical predictors of torsades de pointes induced by almokalant infusion in patients with chronic atrial fibrillation or flutter: A prospective study. PACE 1998;21:1044-1057.

35. Yang P, Kanki H, Drolet B, Yang T, Wei J, Viswanathan PC, Hohnloser SH, Shimizu W, Schwartz PJ, Stanton M, Murray KT, Norris K, George AL Jr, Roden DM. Allelic variants in long-QT disease genes in patients with drugassociated torsades de pointes. Circulation. $2002 \mathrm{Apr}$ 23;105(16):1943-8.

36. Haverkamp W, Breithardt G, Camm AJ, Janse MJ, Rosen MR, Antzelevitch C, Escande D, Franz M, Malik M, Moss A, Shah R. The potential for QT prolongation and proarrhythmia by non-anti-arrhythmic drugs: clinical and regulatory implications report on a policy conference of the European Society of Cardiology. Cardiovasc Res 2000; 47:219-33.

37. Stimmel B. Maintenance therapy for opioid addiction with methadone, LAAM and buprenorphine: The emperor's new clothes phenomenon. J Addict Dis 2001; 20: 714

38. Krantz MJ, Mehler PS. QTc prolongation: methadone's efficacy-safety paradox. Lancet 2006; 368: 556-7.

39. Johnson RE, Chutuape MA, Strain EC, Walsh SL, Stitzer ML, Bigelow GE. A comparison of levomethadyl acetate, buprenorphine, and methadone for opioid dependence. N Engl J Med 2000;343: 1290-7.

Received: May 5, 2008 / Accepted: November 30, 2008

Address for correspondence:

Prof. Dr. N. Scherbaum

Klinik für abhängiges Verhalten und Suchtmedizin

Rheinische Kliniken Essen, Universität Duisburg-Essen

Virchowstr. 174

45147 Essen

Germany

Tel./Fax: +49-201-7227-180/-254

E-mail: norbert.scherbaum@uni-due.de 